\title{
Modeling Growth and Toxin Production of Toxigenic Fungi Signaled in Cheese under Different Temperature and Water Activity Regimes
}

\author{
Marco Camardo Leggieri ${ }^{1}$, Simone Decontardi ${ }^{1}$, Terenzio Bertuzzi ${ }^{2}$, Amedeo Pietri ${ }^{2}$ and \\ Paola Battilani 1,* \\ 1 Department of Sustainable Crop Production-Università Cattolica del Sacro Cuore, Via E. Parmense, 84, \\ 29122 Piacenza, Italy; marco.camardoleggieri@unicatt.it (M.C.L.); simone.decontardi@unicatt.it (S.D.) \\ 2 Institute of Food \& Feed Science and Nutrition-Università Cattolica del Sacro Cuore, Via E. Parmense, 84, \\ 29122 Piacenza, Italy; terenzio.bertuzzi@unicatt.it (T.B.); amedeo.pietri@unicatt.it (A.P.) \\ * Correspondence: paola.battilani@unicatt.it; Tel.: +39-0523-599-254 \\ Academic Editor: Susanne Vogelgsang \\ Received: 1 December 2016; Accepted: 21 December 2016; Published: 24 December 2016
}

\begin{abstract}
The aim of this study was to investigate in vitro and model the effect of temperature (T) and water activity $\left(a_{w}\right)$ conditions on growth and toxin production by some toxigenic fungi signaled in cheese. Aspergillus versicolor, Penicillium camemberti, P. citrinum, P. crustosum, P. nalgiovense, P. nordicum, $P$. roqueforti, $P$. verrucosum were considered they were grown under different $\mathrm{T}\left(0-40{ }^{\circ} \mathrm{C}\right)$ and $a_{w}$ $(0.78-0.99)$ regimes. The highest relative growth occurred around $25^{\circ} \mathrm{C}$; all the fungi were very susceptible to $a_{w}$ and 0.99 was optimal for almost all species (except for $A$. versicolor, $a_{w} o p t=0.96$ ). The highest toxin production occurred between 15 and $25^{\circ} \mathrm{C}$ and $0.96-0.99 a_{w}$. Therefore, during grana cheese ripening, managed between 15 and $22{ }^{\circ} \mathrm{C}$, ochratoxin A (OTA), penitrem A (PA), roquefortine-C (ROQ-C) and mycophenolic acid (MPA) are apparently at the highest production risk. Bete and logistic function described fungal growth under different $\mathrm{T}$ and $a_{w}$ regimes well, respectively. Bete function described also STC, PA, ROQ-C and OTA production as well as function of $\mathrm{T}$. These models would be very useful as starting point to develop a mechanistic model to predict fungal growth and toxin production during cheese ripening and to help advising the most proper setting of environmental factors to minimize the contamination risk.
\end{abstract}

Keywords: Aspergillus; Penicillium; mycotoxin; ochratoxin; sterigmatocystin; roquefortine

\section{Introduction}

Several microorganisms contribute to the features of the final product during cheese-making [1]. The starter microbiota, usually artificially inoculated, is mainly composed of lactic acid bacteria such as Lactococcus lactis [2], which starts the cheese-making process by producing lactic acid and allowing the syneresis of the curd. Moreover, the starter culture degrades the proteins and may produce $\mathrm{CO}_{2}$ in some processes [3]. The secondary microbiota, mainly coming from the environment, or added as for blue cheese [4], becomes dominant after changes in the substrate, i.e., loss of water from the curd, increased salt and $\mathrm{pH}$ [5]. Several types of organisms, like salt-tolerant bacteria, yeasts and filamentous fungi [6-8] contribute to create the sensorial and nutritional characteristics of the final product with their proteolytic and lipolytic activities [4,7]. Some fungi, like Penicillium camemberti and P. roqueforti, are well known as ripening agents in appreciated cheeses [9-11]. Unfortunately, other fungi, e.g., P. nordicum, can act as spoiling agents and/or mycotoxin producers on products of animal origin [12-14], cheese included (Table 1).

Fungal activity is modulated by abiotic and biotic factors [15]; however, knowledge of the ecological needs of fungal mycoflora associated with cheese is poor [16]. Some studies have considered 
the role of temperature $(\mathrm{T})$ on mycotoxin production by cheese-related molds, but generally only a few temperatures and few mycotoxins were considered [17]. Some data are available, regarding citrinin (CIT; [18]), cyclopiazonic acid (CPA; [19,20]), Penitrem A (PA; [21,22]), PR-Toxin [17,23-25] and roquefortine $C$ (ROQ-C; $[20,23,24])$ under defined T regimes. The role of water activity $\left(a_{w}\right)$ and $\mathrm{pH}$ has been poorly studied [16]; ochratoxin A (OTA) production by P. verrucosum on YES medium under different $\mathrm{pH}$ and $a_{w}$ regimes, reported by Schmidt-Heydt, et al. [26], is the only research available.

Therefore, the aim of this study was to investigate and model the ecological needs of some fungi frequently reported as cheese contaminants [27] or commonly used as cheese ripening agents, focusing both on growth and mycotoxin production under different $\mathrm{T}$ and $a_{w}$ regimes. Penicillium camemberti, P. citrinum, P. crustosum, P. nalgiovense, P. nordicum, P. roqueforti, P. verrucosum and Aspergillus versicolor were considered. In a preliminary study, aimed at describing the fungal population associated with cheese during ripening, most of these species were found on the rind of grana type cheeses, sampled during the long aging period.

This is a preliminary study and will contribute to the development of a mechanistic model for the prediction of mycotoxin contamination in ripening cheese.

Table 1. Spoiling agents reported in cheese, mycotoxin produced and their toxic effect.

\begin{tabular}{|c|c|c|c|}
\hline Fungi & Mycotoxin & Toxic Effect & Reported By \\
\hline Aspergillus spp. & Sterigmatocystin (STC) & Carcinogenic, mutagenic [28] & [29-32] \\
\hline P. brevicompactum & Mycophenolic acid (MPA) & Mutagenic, possible acute toxicity [33] & [34] \\
\hline P. camemberti & Cyclopiazonic acid & Neurotoxic, possible acute toxicity [28] & {$[19,35]$} \\
\hline P. crustosum & Penitrem A (PA) & Neurotoxic [28] & [21] \\
\hline P. expansum & Patulin & $\begin{array}{l}\text { Carcinogenic, mutagenic, teratogenic, harmful to liver, } \\
\text { possible acute toxicity [28] }\end{array}$ & {$[39,40]$} \\
\hline P. verrucosum, P. nordicum & Ochratoxin A (OTA) & Nephrotoxic, carcinogenic, hepatotoxic [28] & {$[44]$} \\
\hline
\end{tabular}

\section{Results}

\subsection{Role of Temperature, Water Activity and Incubation Time on Fungal Growth}

\subsubsection{Temperature}

The effect of $\mathrm{T}$ on fungal growth, at different incubation times (0-14 days), is shown in Figure 1 using surface response curves of relative growth; maximum diameter of fungal colony after 1 day incubation is also reported in Table 2.

Fungal growth occurred from 5 to $30{ }^{\circ} \mathrm{C}$ for P. nordicum and P. verrucosum, from 5 to $35^{\circ} \mathrm{C}$ for P. citrinum, P. crustosum, P. nalgiovense and P. roqueforti, from 10 to $30^{\circ} \mathrm{C}$ and from 5 to $25^{\circ} \mathrm{C}$, for A. versicolor and $P$. camemberti, respectively. The highest relative growth occurred with $\mathrm{T}=25^{\circ} \mathrm{C}$ for the majority of fungi, with the exceptions of P. citrinum $\left(\mathrm{T}=30^{\circ} \mathrm{C}\right)$, P. verrucosum and P. nordicum $\left(\mathrm{T}=20^{\circ} \mathrm{C}\right)$. In Table 2, maximum colony growth values after 10-day of incubation are reported for all the selected fungi. This incubation time was considered because one of the fungi ( $P$. roqueforti) reached the maximum possible diameter of $5.5 \mathrm{~cm}$. 


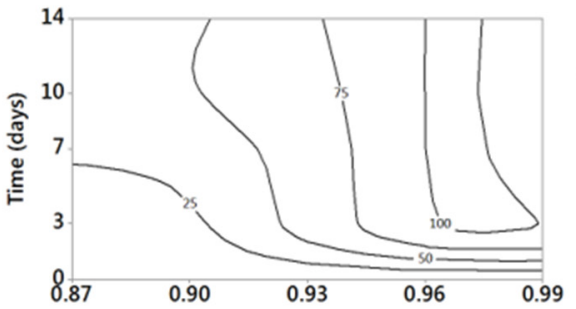

A

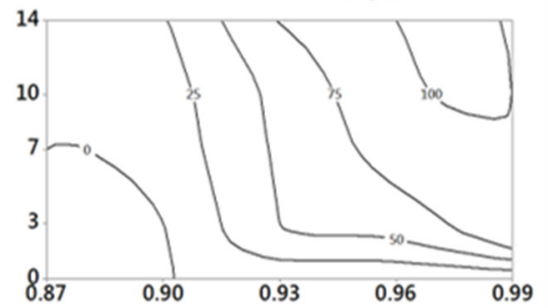

E

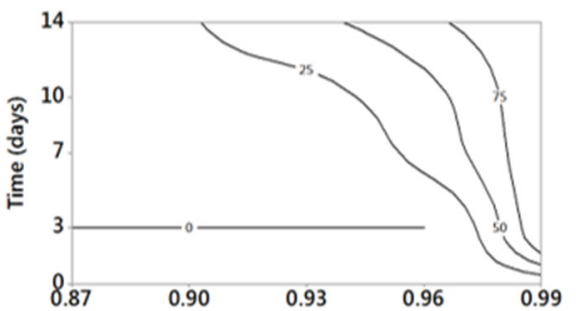

B

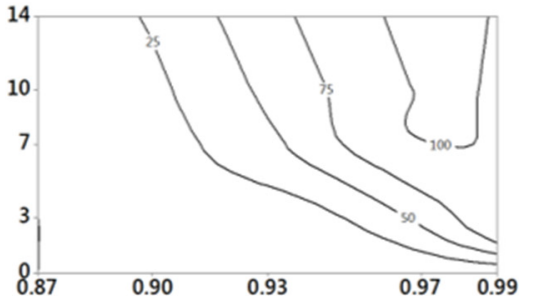

F

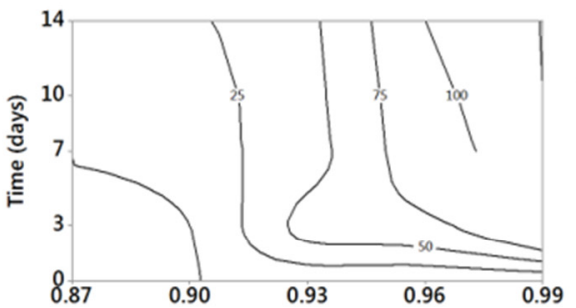

C

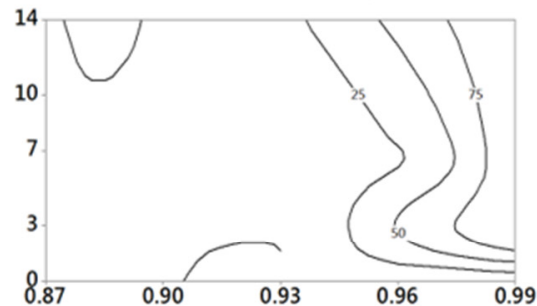

G
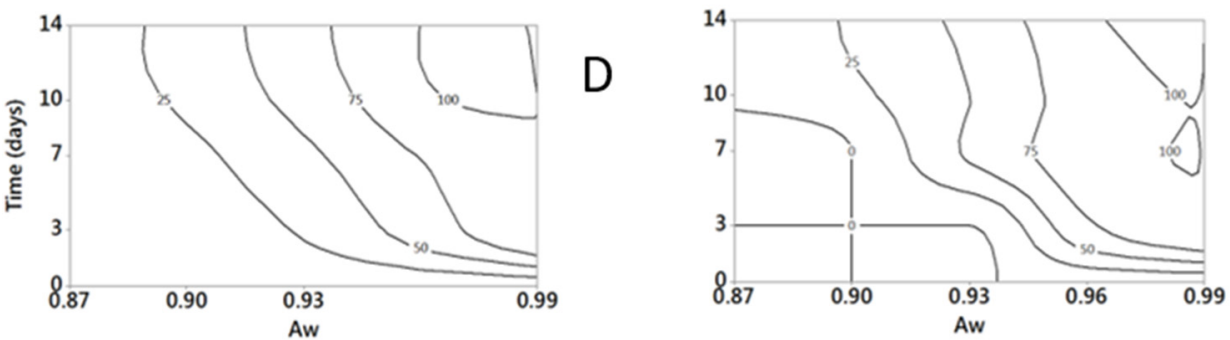

$\mathrm{H}$

Figure 1. Surface response curves of fungal relative growths (expressed as percentage on the maximum growth, numbers on the isoplethes) at different incubation times $(3,7,10,14$ days) under different $\mathrm{T}$ regimes $\left(0-40{ }^{\circ} \mathrm{C}\right.$, step $\left.5{ }^{\circ} \mathrm{C} ; a_{w}=0.99\right)$. (A) A. versicolor; (B) P. camemberti; (C) P. citrinum; (D) P. crustosum; (E) P. nalgiovense; (F) P. nordicum; $(\mathbf{G})$ P. roqueforti; $(\mathbf{H})$ P. verrucosum.

Table 2. Fungal maximum colony diameter $(\mathrm{cm})$ reached after 10 days of incubation at the reported temperature or water activity $\left(a_{w}\right)$, in Experiment 1 and 2, respectively.

\begin{tabular}{ccccc}
\hline \multirow{2}{*}{ Species } & \multicolumn{2}{c}{ Experiment 1. Temperature } & \multicolumn{2}{c}{ Experiment 2. Water Activity } \\
\cline { 2 - 5 } & Diameter Max $(\mathrm{cm})$ & Temperature $\left({ }^{\circ} \mathrm{C}\right)$ & Diameter Max $(\mathrm{cm})$ & $\boldsymbol{a}_{w}$ \\
\hline A. versicolor & 3.1 & 25 & 3.1 & 0.96 \\
P. camemberti & 4.3 & 25 & 4.0 & 0.99 \\
P. citrinum & 4.2 & 30 & 3.1 & 0.99 \\
P. crustosum & 5.1 & 25 & 5.0 & 0.99 \\
P. nalgiovense & 4.8 & 25 & 4.1 & 0.99 \\
P. nordicum & 3.7 & 20 & 3.3 & 0.99 \\
P. roqueforti & 5.5 & 25 & 5.5 & 0.99 \\
P. verrucosum & 4.0 & 20 & 4.0 & 0.99 \\
\hline
\end{tabular}

${ }^{*}$ In experiment 1.Temperature ranged between $0{ }^{\circ} \mathrm{C}$ and $40{ }^{\circ} \mathrm{C}, 5 \pm 1{ }^{\circ} \mathrm{C}$ step and media $a_{w}=0.99$;

** In experiment 2. Water activity ranged between 0.87 and 0.99 , step $0.03 a_{w}$ and $\mathrm{T}=20 \pm 1{ }^{\circ} \mathrm{C}$ 


\subsubsection{Water Activity}

Fungal growth increased with the rise of $a_{w}$, within the range considered $\left(0.87-0.99 a_{w}\right)$, as a general trend for all the species (Figure 2); A. versicolor and P. roqueforti grew from $0.87 a_{w}$, while $a_{w}=0.90$ was the minimum for all the others except $P$. camemberti and P. crustosum. Maximum growth was observed at $0.99 a_{w}$ for all the species except $A$. versicolor, with $0.96 a_{w}$ as optimal. At the optimal $a_{w}$, all the fungal colonies reached maximum diameter between 7 and 14 days; the maximum colony diameters after 10 days of incubation is reported in Table 2.

Incubation times of up to 56 day, applied for $a_{w}=0.87$ and $a_{w}=0.90$, showed P. camemberti, P. crustosum and P. nordicum growth only at $a_{w}=0.90$, while a relevant growth was observed for all the other species at both $a_{w}$ considered.

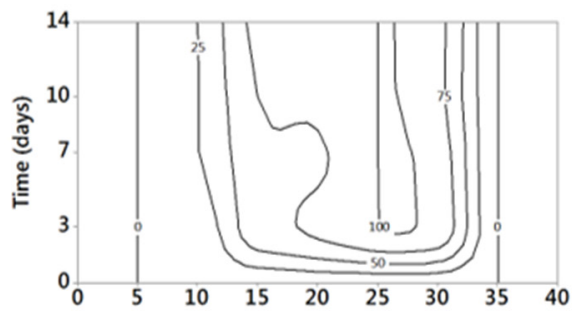

A

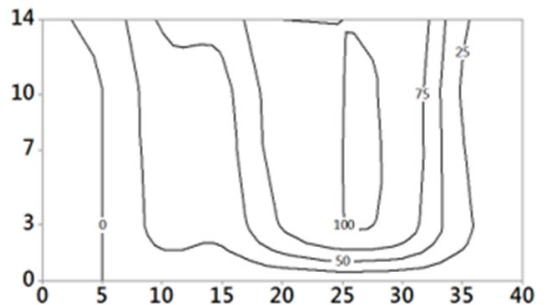

$\mathrm{E}$

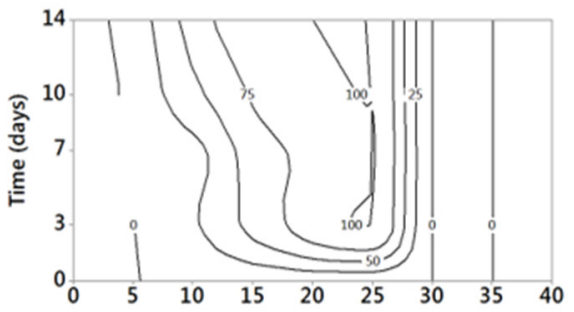

B
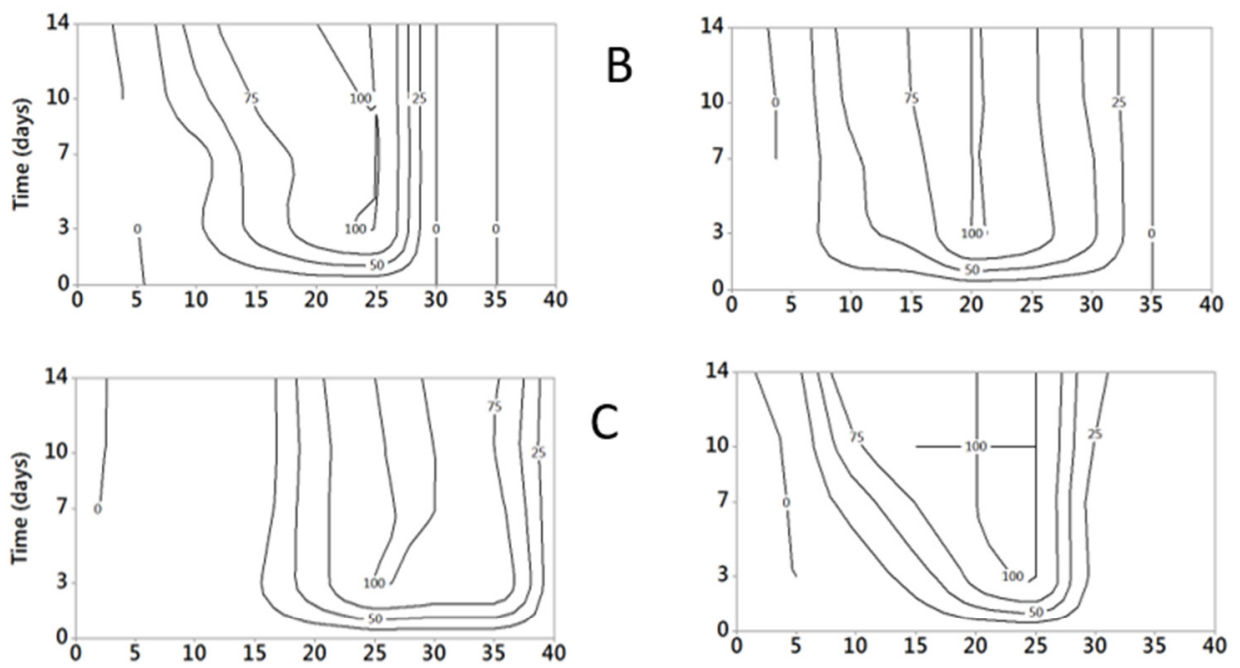

C

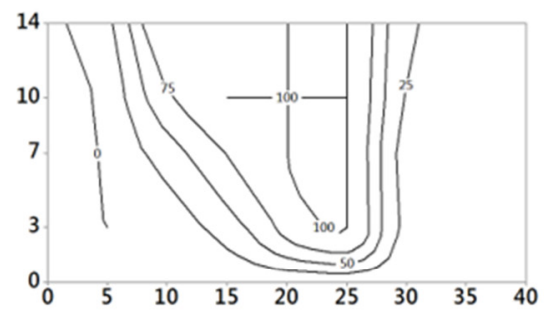

G
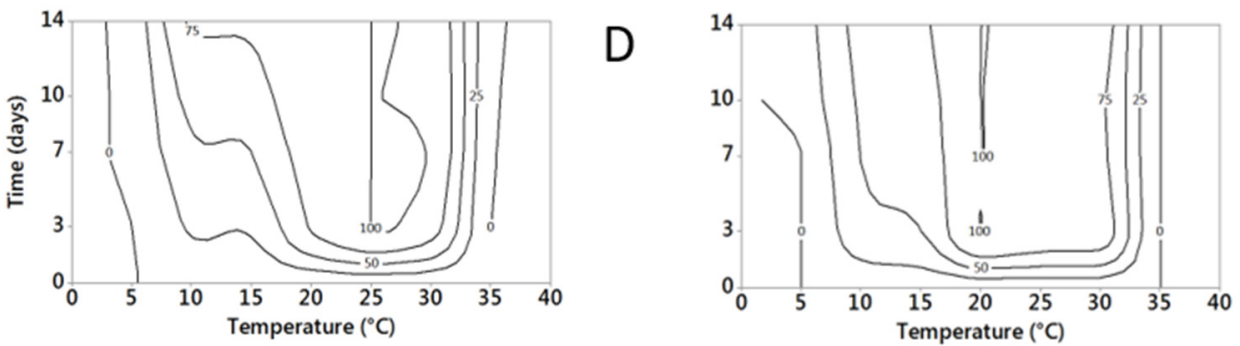

$\mathrm{H}$

Figure 2. Surface response curves of fungal relative growth (expressed as percentage on the maximum growth, numbers on the isoplethes) at different incubation times $(3,7,10,14$ days) under different $a_{w}$ regimes (0.87-0.99; step 0.03; $\left.\mathrm{T}=20^{\circ} \mathrm{C}\right)$. (A) A. versicolor; (B) P. camemberti; (C) P. citrinum; (D) P. crustosum; (E) P. nalgiovense; (F) P. nordicum; (G) P. roqueforti; (H) P. verrucosum.

\subsection{Modeling the Influence of Temperature and Water Activity on Mycelial Growth}

Fungal relative growth for each fungus, in different $\mathrm{T}$ regimes, showed a comparable trend at each incubation time (examples in Figure 3). Therefore, 36 mean relative growth values were used 
for T model fitting ( $9 \mathrm{~T}$ regimes and 4 incubation times, mean of 3 replicates). Regarding $a_{w}$, fungal growth decreased under sub-optimal values and 3 day incubation time was not included in data analysis. Instead of 32 mean relative growth values for $a_{w}\left(8 a_{w}\right.$ regimes and 4 incubation time, mean of 3 replicates), were therefore used 15 mean values ( $5 a_{w}$ regimes and 3 incubation time, mean of 3 replicates) for $a_{w}$ model fitting.

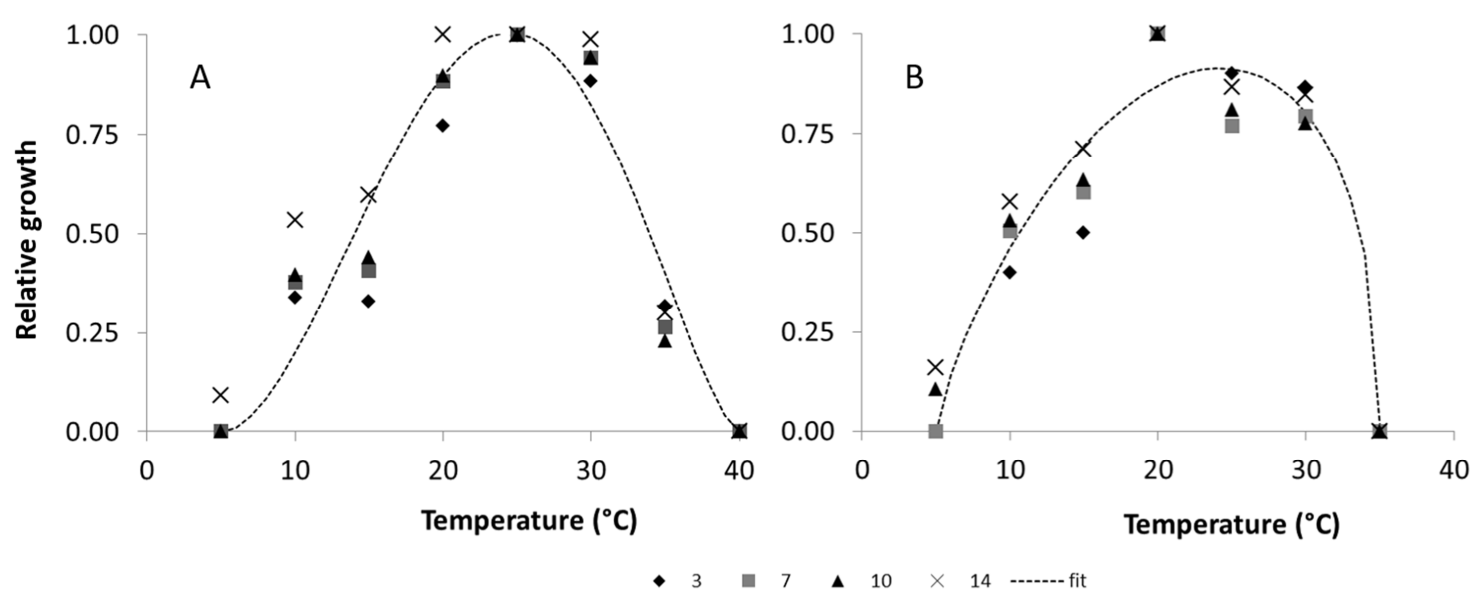

Figure 3. Dynamic of relative growth of (A) P. nalgiovense and (B) P. verrucosum, after 3, 7, 10 and 14 days of incubation, at different temperature regimes $\left(0-40^{\circ} \mathrm{C}\right)$. Data were fitted (dotted line) by a Bete function (see Table 3 for equation parameters).

\subsubsection{Temperature}

The best fitting of fungal growth data as function of $\mathrm{T}$ was obtained, for all fungi considered, by the Bete equation [45] in the form:

$$
y=\left(a *(T e q)^{b} *(1-T e q)\right)^{c}
$$

where $y$ is the relative growth of the colonies, $a, b$ and $c$ are the equations parameters and Teq is the equivalent $\mathrm{T}$ calculated as follows:

$$
\mathrm{Teq}=\left(\mathrm{T}-\mathrm{T}_{\min }\right) /\left(\mathrm{T}_{\max }-\mathrm{T}_{\min }\right)
$$

where $T$ is the temperature regime and $T_{\min }$ and $T_{\max }$ are minimum and maximum temperature, respectively, at which the fungus is able to grow. Parameters, $T_{\min } / T_{\max }$ and $R^{2}$ values are reported in Table 3. The goodness of fit, measured with $R^{2}$, was always good, ranging from 0.798 to 0.96 . Fungal growth increased from $5{ }^{\circ} \mathrm{C}\left(0^{\circ} \mathrm{C}\right.$ for $P$. nordicum $)$ to $20^{\circ} \mathrm{C}$ (P. camemberti, and P. verrucosum) or $25^{\circ} \mathrm{C}$ (A. versicolor, P. crustosum, P. citrinum, P. nalgiovense, P. roqueforti), and then quickly decreased (Figure 4). P. camemberti and P. nordicum showed a very similar behavior, with a fast relative growth up to $25^{\circ} \mathrm{C}$, followed by a rapid decrease (Figure 4). 
Table 3. Parameters of the equations developed to calculate relative growth and mycotoxin production for the selected fungi. The Bete and the logistic equations were used to describe fungal growth respectively as function of temperature $(\mathrm{T})$ and water activity $\left(a_{w}\right)$. The Bete equation was also used to describe relative mycotoxin production as function of $\mathrm{T}$.

\begin{tabular}{|c|c|c|c|c|c|c|}
\hline \multirow{2}{*}{ Fungi } & \multirow{2}{*}{ Variable } & \multirow{2}{*}{$\mathrm{T}_{\min } / \mathrm{T}_{\max }$} & \multicolumn{4}{|c|}{ Estimated Parameters (Standard Error) } \\
\hline & & & $a$ & $b$ & $c$ & $R^{2}$ \\
\hline \multicolumn{7}{|l|}{ Relative Growth } \\
\hline \multirow{2}{*}{ A. versicolor } & $\mathrm{T}$ & $5 / 35$ & $6.85(0.353) *$ & $2.09(0.122)$ & $0.63(0.122)$ & 0.964 \\
\hline & $a_{w}$ & & $-32.719(3.478)$ & $-36.351(3.958)$ & $0.953(0.039)$ & 0.956 \\
\hline \multirow{2}{*}{ P. camemberti } & $\mathrm{T}$ & $5 / 40$ & $3.22(0.150)$ & $0.72(0.049)$ & $4.10(0.779)$ & 0.823 \\
\hline & $a_{w}$ & & $29.12(156.829)$ & $-24.07(11.615)$ & $198.77(32,649.12)$ & 0.925 \\
\hline \multirow{2}{*}{ P. citinum } & $\mathrm{T}$ & $5 / 40$ & $8.03(0.387)$ & $2.33(0.114)$ & $1.12(0.132)$ & 0.961 \\
\hline & $a_{w}$ & & $55.72(8.565)$ & $-59.74(9.294)$ & $1.04(0.053)$ & 0.966 \\
\hline \multirow{2}{*}{ P. crustosum } & $\mathrm{T}$ & $5 / 40$ & $3.95(0.379)$ & $1.01(0.115)$ & $1.24(0.274)$ & 0.798 \\
\hline & $a_{w}$ & & $32.69(8.161)$ & $-34.57(9.079)$ & $1.22(0.233)$ & 0.927 \\
\hline \multirow{2}{*}{ P. nalgiovense } & $\mathrm{T}$ & $5 / 40$ & $4.70(0.245)$ & $1.25(0.074)$ & $1.56(0.209)$ & 0.899 \\
\hline & $a_{w}$ & & $59.29(9.254)$ & $-64.24(10.1)$ & $1.01(0.044)$ & 0.970 \\
\hline \multirow{2}{*}{ P. nordicum } & $\mathrm{T}$ & $0 / 35$ & $5.15(0.200)$ & $1.50(0.063)$ & $1.41(0.14)$ & 0.900 \\
\hline & $a_{w}$ & & $32.72(3.478)$ & $-36.35(3.958)$ & $0.94(0.039)$ & 0.956 \\
\hline \multirow{2}{*}{ P. roqueforti } & $\mathrm{T}$ & $5 / 40$ & $4.26(0.262)$ & $1.08(0.083)$ & $2.45(0.498)$ & 0.902 \\
\hline & $a_{w}$ & & $73.08(44.606)$ & $-75.11(47.168)$ & $1.28(0.601)$ & 0.967 \\
\hline \multirow{2}{*}{ P. verrucosum } & $\mathrm{T}$ & $5 / 35$ & $5.01(0.573)$ & $1.80(0.250)$ & $0.44(0.043)$ & 0.936 \\
\hline & $a_{w}$ & & $58.61(8.441)$ & $-63.15(9.176)$ & $1.03(0.043)$ & 0.979 \\
\hline \multicolumn{7}{|c|}{ Relative Mycotoxin Production } \\
\hline A. versicolor STC & $\mathrm{T}$ & $5 / 35$ & $6.31(1.842)$ & $1.95(0.659)$ & $0.57(0.386)$ & 0.727 \\
\hline P. crustosum PA & $\mathrm{T}$ & $5 / 35$ & $4.78(0.457)$ & $1.31(0.145)$ & $2.19(0.607)$ & 0.942 \\
\hline P. crustosum ROQ-C & $\mathrm{T}$ & $5 / 35$ & $5.14(0.330)$ & $1.43(0.103)$ & $1.53(0.258)$ & 0.981 \\
\hline P. nordicum OTA & $\mathrm{T}$ & $5 / 35$ & $3.65(0.138)$ & $0.87(0.042)$ & $1.79(0.185)$ & 0.991 \\
\hline P. roqueforti ROQ-C & $\mathrm{T}$ & $5 / 35$ & $5.19(0.440)$ & $1.48(0.139)$ & $0.79(0.161)$ & 0.986 \\
\hline P. verrucosum OTA & $\mathrm{T}$ & $5 / 35$ & $6.30(0.224)$ & $1.72(0.066)$ & $0.87(0.074)$ & 0.998 \\
\hline
\end{tabular}
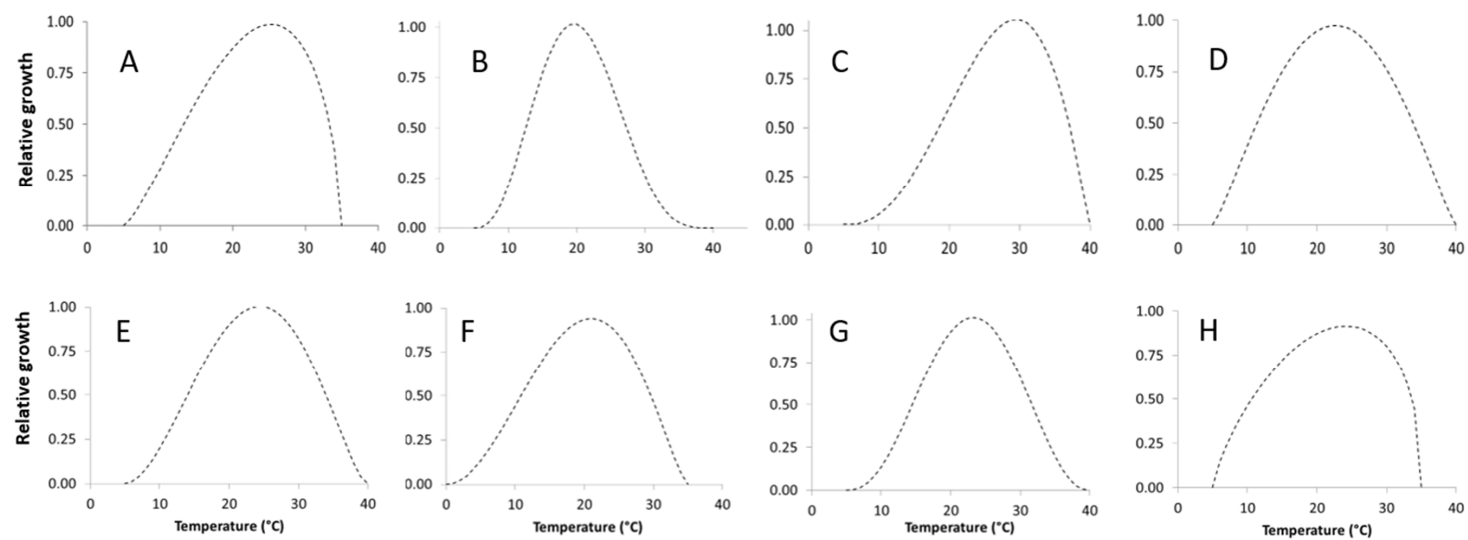

Figure 4. Dynamic of relative growth of the studied fungi, at different temperature regimes $\left(0-40{ }^{\circ} \mathrm{C}\right)$. Data were fitted by a Bete function (see Table 3 for equation parameters). (A) A. versicolor; (B) P. camemberti; (C) P. citrinum; (D) P. crustosum; (E) P. nalgiovense; (F) P. nordicum; (G) P. roqueforti; (H) P. verrucosum.

\subsubsection{Water Activity}

The influence of different $a_{w}$ regimes on fungal growth was well described using a Logistic equation, in the following form:

$$
y=c /\left(1+\exp ^{\left(a+b * a_{w}\right)}\right)
$$


in which $y$ is the fungal relative growth, $a, b$, and $c$ are equation parameters, reported in Table 3 . All fungi showed an S-shaped growth, except P. camemberti and P. roqueforti, with a J-shaped trend [46], without the upper plateau (Figure 5). The functions developed showed a very good fitting to growth data with $R^{2}$ ranging between 0.925 and 0.979 .
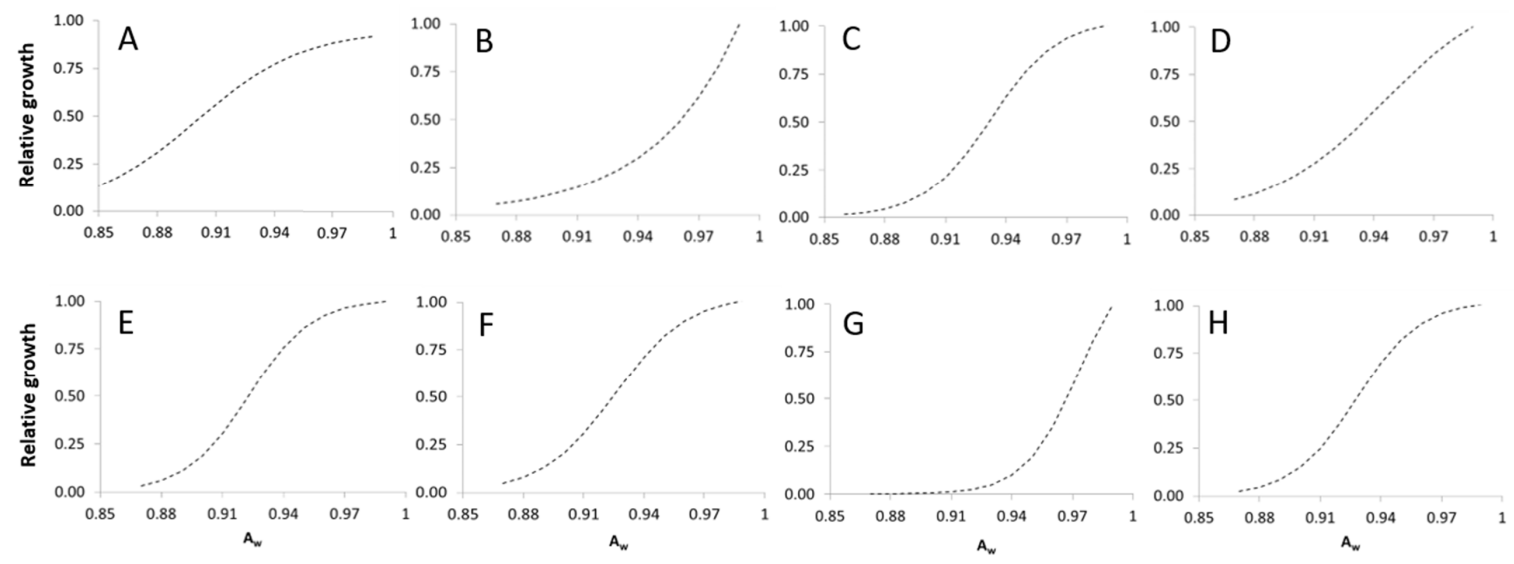

Figure 5. Logistic equations (lines, refer to Table 3 for equation parameters) defining the dynamics of fungal growth at different $\mathrm{a}_{\mathrm{w}}$ regimes (0.78-0.99). (A) P. versicolor; (B) P. camemberti; (C) P. citrinum; (D) P. crustosum; (E) P. nalgiovense; (F) P. nordicum; (G) P. roqueforti; (H) P. verrucosum. (for Figure 5A suitable $\mathrm{a}_{\mathrm{w}}$ start from 0.78 but the same range of other fungi was used).

\subsection{Modeling the Combined Effect of Temperature and Water Activity on Mycelial Growth}

The combined effect of $\mathrm{T}$ and $a_{w}$ was also considered, merging the functions previously developed, as follows:

$$
y=\mathrm{a}_{\mathrm{T}} \times T e q^{\mathrm{b}_{\mathrm{T}}} \times(1-\mathrm{Teq})^{\mathrm{c}_{\mathrm{T}}} \times c_{a_{w}} /\left(1+\exp ^{\left(a_{a_{w}}+b_{a_{w}} * a_{w}\right)}\right)
$$

in which $y$ is the relative growth, computed referring to the maximum growth observed.

The output was plotted in a single chart (Figure 6), where the curves represent the combination of conditions that allow to reach $50 \%$ relative growth, for each fungus, as function of $\mathrm{T}$ and $a_{w}$.

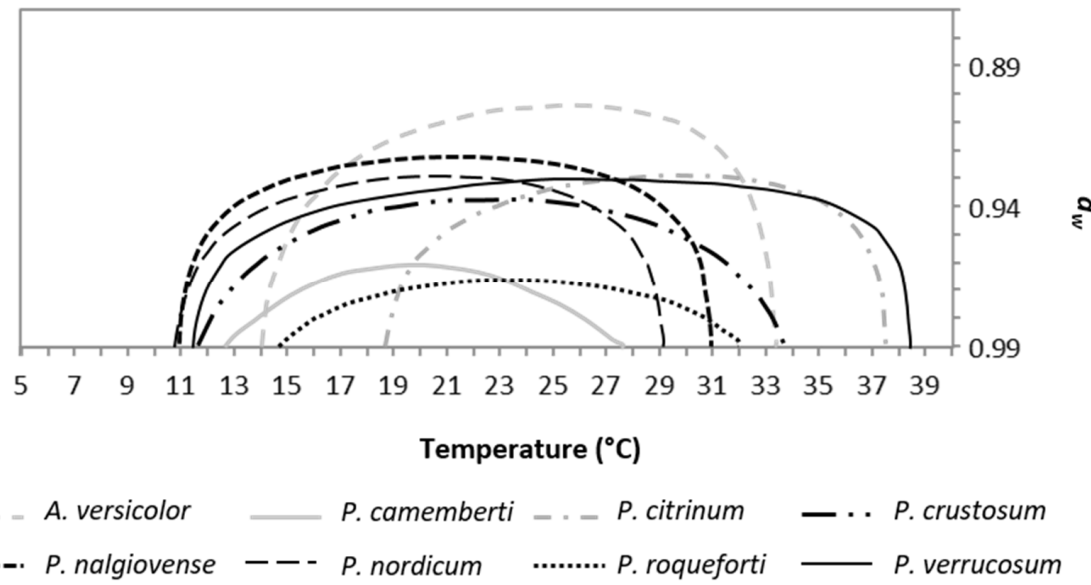

Figure 6. Boundaries, derived from Equation (4), summarizing the combination of $\mathrm{T}$ and $\mathrm{a}_{\mathrm{w}}$ conditions to reach relative growth $=0.5$ for each fungus considered in the study.

Focusing attention on $\mathrm{T}$ values, the number of fungal species able to grow increased from $10{ }^{\circ} \mathrm{C}$ up to $20^{\circ} \mathrm{C}$, then decreased starting from $27^{\circ} \mathrm{C}$. P. nordicum started growth from $10^{\circ} \mathrm{C}$, immediately followed by P. nalgiovense, P. verrucosum, P. crustosum, P. camemberti, A. versicolor, P. roqueforti (from 
$14^{\circ} \mathrm{C}$ ), and P. citrinum (from $19^{\circ} \mathrm{C}$ ). All fungi were able to grow between 20 and $27^{\circ} \mathrm{C}$. Then, moving to higher temperatures, $P$. camemberti was the first to reduce the relative growth below $50 \%$ (T limit around $\left.27^{\circ} \mathrm{C}\right)$, followed by P. nordicum $\left(29^{\circ} \mathrm{C}\right)$, P. nalgiovense $\left(31^{\circ} \mathrm{C}\right)$, P. roqueforti $\left(32^{\circ} \mathrm{C}\right)$, A versicolor and P. crustosum $\left(34^{\circ} \mathrm{C}\right)$, P. citrinum and P. verrucosum $\left(37-39^{\circ} \mathrm{C}\right)$.

Considering $a_{w}$, the number of species with growth $>50 \%$ gradually decreased as $a_{w}$ values moved from 0.99 to 0.87 . P. roqueforti showed a relative growth below $50 \%$ at $0.97 a_{w}$, followed by $P$. camemberti and P. crustosum (0.96 and $0.94 a_{w}$ respectively), P. citrinum, P. nalgiovense, P. nordicum, and P. verrucosum (around $\left.0.93 a_{w}\right)$ and A. versicolor $\left(0.90 a_{w}\right)$.

\subsection{Influence of Temperature and Water Activity on Mycotoxin Production}

All the mycotoxins investigated were detected $\left(\mu \mathrm{g} / \mathrm{L}>\mathrm{LOD}\right.$ ) and reported in $\mathrm{ng} / \mathrm{mm}^{2}$ (Table 4), except CPA, PR and CIT in P. citrinum, P. roqueforti and P. verrucosum, respectively. Significant differences in the produced amount of toxins, depending on the fungus and ecological conditions tested, were noticed, except for CIT produced by P. camemberti. In particular, the optimum temperature for mycotoxin production was commonly between 20 and $25^{\circ} \mathrm{C}$, and the optimum $a_{w}$ was 0.99 , except for MPA optimally produced by P. roqueforti at the combination $20^{\circ} \mathrm{C}$ and $0.96 a_{w}$. No mycotoxin was detected in fungal colonies grown with $a_{w}<0.93$ after the 14-day incubation.

\subsection{Modeling the Effect of Temperature and Water Activity on Toxin Production}

\subsubsection{Temperature}

The best fitting of toxin production data as function of $\mathrm{T}$ was obtained by the Bete equation (Equation (1); [45]). Good results are reported for STC produced by A. versicolor, OTA produced by P. nordicum and P. verrucosum, PA produced by P. crustosum and ROQ-C produced by P. crustosum and P. roqueforti (Table 3, Figure 7), with $R^{2} \geq 0.94$ for all fungi except $A$. versicolor $\left(R^{2}=0.727\right)$.

Regarding the other fungi/toxins, toxin production was possible only for a few temperature regimes (i.e., ROQ-C and MPA produced by $P$. roqueforti). Therefore, no data modeling was performed.

\subsubsection{Water Activity}

The range of $a_{w}$ that allowed toxin production was limited to $0.93-0.99$, with only 3 points available. Therefore, no modeling was applied to this dataset.

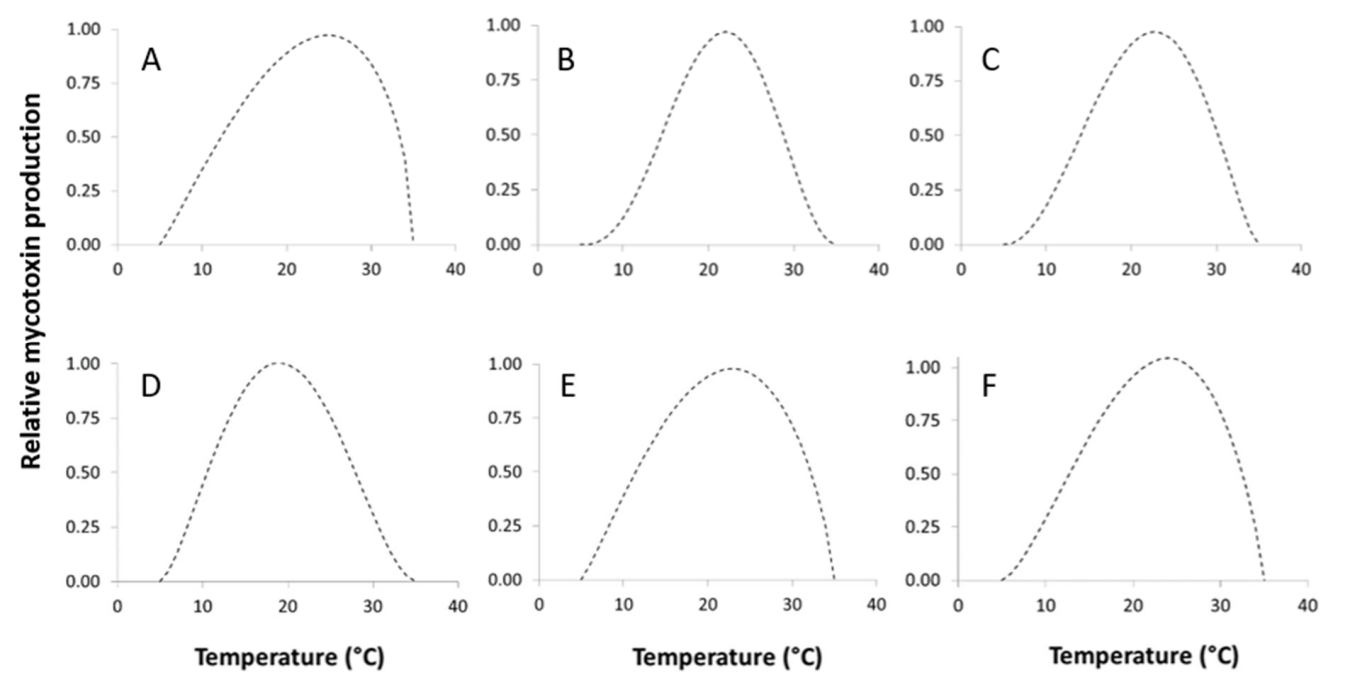

Figure 7. Dynamic of mycotoxins production rate for: (A) STC - A. versicolor; (B) PA-P. crustosum; (C) ROQ-C-P. crustosum; (D) OTA-P. nordicum; (E) ROQ-C-P. roqueforti; (F) OTA-P. verrucosum, at different temperature regimes $\left(5-35^{\circ} \mathrm{C}\right)$. Data were fitted by a Beta function (see Table 3 for details). 
Table 4. Mycotoxin production under different regimes of temperature (T) and water activity $\left(a_{w}\right)$ after 14 days of incubation. Data are reported as mean ng of toxin produced per $\mathrm{mm}^{2}$ of fungal colony area ( $\mathrm{ng} / \mathrm{mm}^{2}$; three replicates).

\begin{tabular}{|c|c|c|c|c|c|c|c|c|c|c|c|c|c|c|c|c|c|c|c|c|c|c|}
\hline \multirow[b]{2}{*}{$\mathrm{T}\left({ }^{\circ} \mathrm{C}\right)$} & \multirow[b]{2}{*}{$a_{w}$} & \multicolumn{2}{|c|}{ A. versicolor } & \multicolumn{3}{|c|}{ P. camemberti } & \multirow{2}{*}{\multicolumn{2}{|c|}{$\begin{array}{c}\text { P. citrinum } \\
\text { CIT }\end{array}$}} & \multicolumn{4}{|c|}{ P. crustosum } & \multirow{2}{*}{\multicolumn{2}{|c|}{$\begin{array}{c}\text { P. nordicum } \\
\text { OTA }\end{array}$}} & \multicolumn{5}{|c|}{ P. roqueforti } & \multicolumn{3}{|c|}{ P. verrucosum } \\
\hline & & \multicolumn{2}{|c|}{ STC } & CIT & \multicolumn{2}{|c|}{ CPA } & & & \multicolumn{2}{|c|}{ PA } & \multicolumn{2}{|c|}{ ROQ } & & & \multicolumn{2}{|c|}{ MPA } & \multicolumn{2}{|c|}{ ROQ } & \multirow[t]{2}{*}{ PR } & \multirow[t]{2}{*}{ CIT } & \multicolumn{2}{|c|}{ OTA } \\
\hline \multicolumn{21}{|c|}{ Temperature } & & \\
\hline 5 & 0.99 & $<\mathrm{LOD}^{\#}$ & $a^{+}$ & 1.1 & $<$ LOD & $a$ & 0.9 & $a$ & 7.4 & $b$ & 6.7 & $a$ & $<$ LOD & $a$ & $<\mathrm{LOD}$ & $a$ & $<$ LOD & $a$ & $<$ LOD & $<\mathrm{LOD}$ & $<\mathrm{LOD}$ & $a$ \\
\hline 10 & 0.99 & 7.4 & $b c$ & 1.0 & 0.5 & $a$ & 66.8 & $b$ & 31.7 & $c$ & 237.4 & $b$ & 0.2 & $a$ & 0.9 & $c$ & 112.3 & $b$ & $<\mathrm{LOD}$ & $<\mathrm{LOD}$ & $<\mathrm{LOD}$ & $a$ \\
\hline 15 & 0.99 & 16.9 & $c$ & 0.7 & 0.4 & $a$ & 63.8 & $b$ & 150.9 & $e$ & 630.8 & $b c$ & 4.0 & $b$ & 1.7 & $d$ & 246.9 & $c$ & $<\mathrm{LOD}$ & $<$ LOD & 0.8 & $b$ \\
\hline 20 * & 0.99 & 81 & $d$ & 3.8 & 7.6 & $b$ & 1187.8 & $c$ & 152.7 & $e$ & 679.5 & $c$ & 9.0 & $b$ & 0.4 & $b$ & 324.9 & $d$ & $<\mathrm{LOD}$ & $<\mathrm{LOD}$ & 4.6 & d \\
\hline 25 & 0.99 & 91.4 & $d$ & 0.5 & 20.3 & c & 1147.5 & $c$ & 197.2 & $e$ & 824.3 & $c$ & 3.7 & $b$ & $<\mathrm{LOD}$ & $a$ & 282.0 & $d$ & $<\mathrm{LOD}$ & $<\mathrm{LOD}$ & 12.6 & $e$ \\
\hline 30 & 0.99 & 284 & $e$ & $<\mathrm{LOD}$ & $<$ LOD & $a$ & 1728.9 & $c$ & 81.8 & $d$ & 615.6 & $b c$ & 0.1 & $a$ & $<$ LOD & $a$ & 248.0 & $c$ & $<\mathrm{LOD}$ & $<$ LOD & 2.5 & $c$ \\
\hline 35 & 0.99 & 6.6 & $b$ & $<$ LOD & $<\mathrm{LOD}$ & $a$ & 2918.1 & $c$ & $<\mathrm{LOD}$ & $a$ & $<\mathrm{LOD}$ & $a$ & $<\mathrm{LOD}$ & $a$ & $<\mathrm{LOD}$ & $a$ & 0.1 & $a$ & $<\mathrm{LOD}$ & $<\mathrm{LOD}$ & $<\mathrm{LOD}$ & $a$ \\
\hline \multicolumn{23}{|c|}{ Water activity } \\
\hline 20 & 0.93 & \multicolumn{2}{|c|}{$<\mathrm{LOD}$} & $<\mathrm{LOD}$ & \multicolumn{2}{|c|}{$<\mathrm{LOD}$} & 73 & & \multicolumn{2}{|c|}{25.6} & \multicolumn{2}{|c|}{149.0} & $<\mathrm{LC}$ & & \multicolumn{2}{|c|}{$<\mathrm{LOD}$} & \multicolumn{2}{|c|}{68.2} & $<\mathrm{LOD}$ & $<$ LOD & \multicolumn{2}{|c|}{$<\mathrm{LOD}$} \\
\hline 20 & 0.96 & \multicolumn{2}{|c|}{4.4} & 1.0 & \multicolumn{2}{|c|}{0.3} & \multicolumn{2}{|c|}{100.2} & \multicolumn{2}{|c|}{59.6} & 644. & & 0. & & 21.1 & & 335 & & $<\mathrm{LOD}$ & $<\mathrm{LOD}$ & $<\mathrm{L}$ & \\
\hline
\end{tabular}

$*$ data collected at $20{ }^{\circ} \mathrm{C}$ and $0.99 a_{w}$ are common for the trial at different $\mathrm{T}$ and
${ }^{+}$Different letters define significant difference according to Tukey test $(p \leq 0.01)$. 


\section{Discussion}

The ripening of hard cheese is carried out commonly in a temperature range from 10 to $20^{\circ} \mathrm{C}$, as defined in the guidelines of many products Protected for Denomination of Origin, e.g., Fontina, Fiore Sardo and Emmentaler. For Italian grana type cheeses, the environmental conditions during aging are between $15^{\circ} \mathrm{C}$ and $22^{\circ} \mathrm{C}$, as reported in the "Parmigiano Reggiano" and "Grana Padano" cheese production guidelines (www.politicheagricole.it). Grana cheeses are long-ripened high quality products; according to preliminary unpublished data, starting from 9 month storage, the $a_{w}$ varies between 0.92 and 0.85 in the crust and between 0.94 and 0.87 if a wider layer is considered, while the relative humidity of storehouses ranges between $72 \%$ and $88 \%$.

Most of the fungi studied grew optimally around $25^{\circ} \mathrm{C}$, but for $P$. citrinum the relative growth was higher at $30^{\circ} \mathrm{C}$, and for P. verrucosum and P. nordicum at $20^{\circ} \mathrm{C}$. The susceptibility to $a_{w}$ regimes was considerable; $a_{w}=0.99$ was optimal for all species except the more xerophilic $A$. versicolor, which grew best with $a_{w}=0.96$. A versicolor, $P$ citrinum, $P$. nalgiovense, $P$. roqueforti and $P$. verrucosum grew down to $0.87 a_{w} ; a_{w}=0.90$ was the limit for P. nordicum and P. camemberti and $a_{w}=0.94$ for P. crustosum, even at the longest incubation times considered in this study (56 days).

Therefore, all fungi studied can grow in the range of $\mathrm{T}$ common for the storage of hard, long maturing grana type cheeses. Recently Marin, et al. [47] reported Penicillium spp. as the dominant species on hard cheese; Penicillium and Aspergillus spp. were highly tolerant to water restriction, making them more competitive with other fungi during cheese ripening. This is confirmed in this study, where the lower $\mathrm{a}_{\mathrm{w}}$ limit for growth was 0.87 for several Penicillium species and for A. versicolor.

Fungal growth in artificial media with modified $a_{w}$, as managed in this study, possibly suffered from the high amount of salt supplemented in the lowest $a_{w}$ regimes. It is well know that compounds added to modify $a_{w}$ (glycerol or $\mathrm{NaCl}$ ), interfere with fungal metabolism, the former enhancing fungal growth, being a carbon source, and the latter becoming toxic for fungi at high dosages [47-49]. Toxicity more than $a_{w}$ could have limited the fungal activity of some Penicillium species; therefore, further trials on cheese will be required to define cardinal $a_{w}$ regimes.

No toxin production is reported in literature for P. nalgiovense; this fungus was not considered for mycotoxin analysis, but only to check its potential competition with other fungi. It was noticed that it was more xerophilic than other Penicillia studied and showed more than $50 \%$ relative growth up to $a_{w}=0.93$ after 14 days of incubation. Penicillium nalgiovense and P. crustosum were the fastest growing fungi at $10^{\circ} \mathrm{C}$, P. citrinum and P. nordicum at $5^{\circ} \mathrm{C}$. Growth speed is important because it favors fungi competiveness. Therefore, these data suggest that $P$. nalgiovense could effectively compete with other fungi present in cheese, depending on the abiotic conditions of exposure.

As well-known from literature, the range of abiotic conditions that allows toxin production is commonly narrow than that allowing growth and this is confirmed in the present study. CPA and MPA production started at $10^{\circ} \mathrm{C}$, while P. camemberti and P. roqueforti grew from $5{ }^{\circ} \mathrm{C}$. OTA production started at 10 and $15^{\circ} \mathrm{C}$, respectively for P. nordicum and P. verrucosum, while growth was observed from $5{ }^{\circ} \mathrm{C}$. MPA was detected up to $20^{\circ} \mathrm{C}$, while growth continued up to $30^{\circ} \mathrm{C}$.

Water activity resulted as the most limiting factor for toxin production; in fact, growth was observed down to $0.87-0.90 a_{w}$, depending on the fungal species, while toxin production stopped at $0.93 a_{w}$ for CIT, PR and ROQ-C, $0.99 a_{w}$ for OTA by P. verrucosum and $0.96 a_{w}$ for all the other fungi.

Even though toxic metabolites have been reported in $P$. camemberti and P. roqueforti, they are used as ripening agents, and CIT, CPA, MPA and ROQ-C were effectively detected in fungal cultures in the range of conditions considered in this study. Therefore, strains included in starter inocula should be preliminarily checked for toxigenicity. This can be inferred also from Dall'Asta, de Dea Lindner, Galaverna, Dossena, Neviani and Marchelli [44], who found OTA contamination increased duiring storage of blue cheeses.

CIT is the toxin detected in the highest amount in this study, around $3000 \mathrm{ng} / \mathrm{mm}^{2}$ of fungal colony, in P. citrinum grown at $35^{\circ} \mathrm{C}$ and $0.99 a_{w}$. CIT was produced at all the temperature conditions 
considered, in agreement with Bailly, Querin, Le Bars-Bailly, Benard and Guerre [18], while it rapidly decreased from 1200 to $100 \mathrm{ng} / \mathrm{mm}^{2}$ when $a_{w}$ moved from 0.99 to $0.96\left(\mathrm{~T}=20^{\circ} \mathrm{C}\right)$.

CIT production by P. camemberti is a matter of concern because it was detected at $5{ }^{\circ} \mathrm{C}$, T typically applied for home storage by consumers. Fortunately, according to Manabe [50], few P. camemberti strains were able to produce CIT. No CIT was produced in the present study by P. verrucosum, even if previously reported $[27,51]$. This could be due to its susceptibility to salt concentration. According to Schmidt-Heydt, et al. [26], when salt concentration is equal to or above $20 \mathrm{~g} / \mathrm{L}, P$. verrucosum shifts from producing CIT to OTA. As the amount of $\mathrm{NaCl}$ used to modify the $a_{w}$ in our study was about $70 \mathrm{~g} / \mathrm{L}$ minimum, lacking of CIT production at different $a_{w}$ regimes is not surprising.

PA, typically produced by P. crustosum, was detected in all the considered conditions except at $35^{\circ} \mathrm{C}$, with the optimum at $25^{\circ} \mathrm{C}$, in agreement with Larsen, et al. [52] and Kokkonen, et al. [53].

ROQ-C and MPA are typically P. roqueforti extrolites [23,24,27], but ROQ-C is also produced by P. crustosum $[54,55]$. ROQ-C was produced by $P$. roqueforti at all the considered conditions. Several authors agree on the very high incidence of toxigenic strains in P. roqueforti populations [23,24,56,57]. Significant reduction in ROQ-C was observed with T lower than $12{ }^{\circ} \mathrm{C}, \mathrm{NaCl}$ concentrations $8 \%$ and modified atmosphere $\left(1 \%-5 \% \mathrm{O}_{2}\right.$ and $\left.20 \%-40 \% \mathrm{CO}_{2} ;[48]\right)$. A substantial support in describing the role of abiotic factors will come from the genome of $P$. roqueforti recently published [58].

STC, a very stable compound [59], has so far only beendetected on the rind of hard cheeses [31]. In this study, STC was produced by $A$. versicolor over the T range $10-35{ }^{\circ} \mathrm{C}$ and with $a_{w} \geq 0.96$, but STC production with lower $\mathrm{a}_{\mathrm{w}}$ cannot be excluded in cheese.

CPA was supposed to be produced by P. citrinum and by P. camemberti, but it was only detected in the latter colonies, incubated between 10 and $25{ }^{\circ} \mathrm{C}$ and with $a_{w} \geq 0.96$. The amount of CPA measured increased with temperature and $a_{w}$ increase, in agreement with Le Bars [19] who also confirmed the high incidence of toxigenic strains in P. camemberti populations.

Penicillium nordicum and P. verrucosum are OTA producers and in this study, as expected, P. nordicum was more efficient at slightly lower $\mathrm{T}$ and higher $a_{w}, 0.96-0.99$, compared to P. verrucosum. The latter resulted toxigenic also at very low $a_{w}, 0.87-0.93$, with a long incubation time, in agreement with Schmidt-Heydt et al. [60] and Schmidt-Heydt, et al. [26]. They also underlined the efficacy of salt addition in limiting OTA production by P. nordicum. Since the ambient T and the cheese rind $a_{w}$ during cheese ripening are favorable, possible contaminations by P. nordicum and P. verrucosum must not be underrated, even if OTA is sometimes undetectable [56].

Growth and toxin production rates by the studied fungi was well described by Bete function and by logistic regression in different $\mathrm{T}$ and $a_{w}$ regimes, respectively. The Bete equation is in agreement with good modelling results obtained by Rossi, et al. [61] for fungi involved in Fusarium head blight complex and deoxynivalenol and zearalenon production, by Nazari, et al. [62] for Fusarium langsethiae/F. sporotrichioides and T-2/HT-2 toxins production, by Battilani, et al. [63] to model A. flavus growth on maize and recently for A. carbonarius growth on grapes [64]. Other modeling approaches are described in literature to predict fungal growth as T function $[65,66]$, but the use of Bete equation is more advisable when functions are developed to be used for mechanistic model development [67]. Furthermore, Bete equation was used to model other key steps of fungal infection cycle as function of $\mathrm{T}$, like A. flavus sporulation [68] and A. carbonarius germination. However, further tests of growth on cheese will be necessary to develop a good model.

\section{Conclusions}

The highest risk of toxin production in cheese should occur between 15 and $25^{\circ} \mathrm{C}$, where 4 out of 8 of the species considered in this study had their optimal toxigenic activity. In particular, between 15 and $22{ }^{\circ} \mathrm{C}, 3$ fungi, P. crustosum, P. nordicum and P. roqueforti, are expected to cause major problems, with OTA, PA, ROQ-C and MPA as expected toxins. STC and CIT should also be monitored, even if their production is optimized with higher T regimes. Regarding $a_{w}$, if the cheese rind has an $a_{w}$ below 0.93 , mycotoxin production should not be at very high risk, at least within the first 2 weeks 
of development of a spoiling mold. Nevertheless, some contamination data reported in literature after long ripening periods are in contrast with this statement. This study underlines two important factors regarding mycotoxin-producting fungi in cheese: (i) they can grow in conditions comparable with those used for cheese ripening and (ii) a multi-mycotoxin contamination of cheese is possible. Therefore, the models developed in this study should be validated/adjusted with data obtained on cheese. This will be a good starting point to develop a model to predict contamination by different mycotoxins. In the meantime, monitoring ripened cheese for toxin contamination is strongly suggested, especially when their presence will be predicted on the basis of abiotic and biotic data.

\section{Materials and Methods}

\subsection{Fungal Strains}

The fungi included in this study are all toxigenic, except for $P$. nalgiovense, which is however considered because of its prevalence in ripened pork meat and signaled in cheese, and as a possible competitor of toxigenic species. Characterized strains were purchased from CBS-NAW fungal collection (http://www.cbs.knaw.nl/; Table 5).

Table 5. Fungal strains and related mycotoxins considered in this study.

\begin{tabular}{ccc}
\hline Species & Code & Mycotoxin (Abbreviation) \\
\hline A. versicolor & CBS 108959 & Sterigmatocystin (STC) \\
P. camemberti & CBS 122399 & Citrinin (CIT), Cyclopyazonic Acid (CPA) \\
P. citrinum & CBS 122396 & CIT, CPA \\
P. crustosum & CBS 115503 & Penitrem A (PA), Roquefortine C (ROQ-C) \\
P. nalgiovense & CBS 109609 & \# \\
P. nordicum & CBS 112573 & Ochratoxin A (OTA) \\
P. roqueforti & CBS 221.30 & Mycophenolic Acid (MPA), ROQ-C, PR Toxin (PR-TOXIN) \\
P. verrucosum & CBS 325.92 & CIT, OTA \\
\hline
\end{tabular}

\# No toxins are reported for this fungus.

\subsection{Culture Media}

Ingredients for media were purchased from Himedia Laboratories (Mumbai, India).

Czapek Yeast Agar (CYA, [69]), supplemented with sodium chloride ( $\mathrm{NaCl})$ (Carlo Erba, Milan, Italy) to modify the original $a_{w}=0.99$, was used to perform the ecological trials (Table 6).

Table 6. Amounts of sodium chloride $(\mathrm{NaCl})$ added to Ckzapek Yeast Agar (CYA) to modify medium water activity $\left(a_{w} ;[70]\right)$.

\begin{tabular}{cc}
\hline $\mathrm{NaCl}(\mathrm{g} / \mathbf{1 0 0} \mathbf{~ m L})$ & $\boldsymbol{a}_{w}$ \\
\hline $\mathbf{7 . 0 1}$ & 0.96 \\
$\mathbf{1 1 . 9 8}$ & 0.93 \\
$\mathbf{1 6 . 5 6}$ & 0.90 \\
$\mathbf{1 9 . 4 0}$ & 0.87 \\
$\mathbf{2 3 . 5 5}$ & 0.84 \\
$\mathbf{3 0 . 1 0}$ & 0.81 \\
$\mathbf{3 9 . 9 0}$ & 0.78 \\
\hline
\end{tabular}

\subsection{Inoculum Preparation, Inoculation and Incubation}

A conidia suspension was prepared using 7-day old colonies grown on Malt Extract Agar, (MEA, [71]). The spores were collected using $20 \mathrm{~mL}$ of sterile bi-distilled water added to each Petri dish, gently agitating the culture to remove conidia. The suspension was adjusted to a concentration of $10^{6}$ spores/mL using an haemocytometer, in agreement with fungal CFU/g detected in naturally 
contaminated cheese. Then, $10 \mu \mathrm{L}$ of conidial suspension of each strain was centrally inoculated in $60 \mathrm{~mm} \varnothing$ Petri plates and incubated in the proper conditions; the trial was managed in triplicate.

Two experiments were performed to assess the role of: (i) $\mathrm{T}$ and (ii) $a_{w}$ on fungal growth and mycotoxin production.

Regarding T, CYA inoculated plates, all prepared without any $a_{w}$ modification, were incubated at temperatures ranging between $0{ }^{\circ} \mathrm{C}$ and $40{ }^{\circ} \mathrm{C}, 5 \pm 1{ }^{\circ} \mathrm{C}$ step, for 14 days.

Regarding $a_{w}$, the CYA medium was adjusted to $a_{w}$ values from 0.87 to 0.99 step $0.03 a_{w}$, and incubated at $20 \pm 1{ }^{\circ} \mathrm{C}$ for 14 days. Longer incubation times, up to 56 days, were considered for the $a_{w}$ regimes $\leq 0.90$.

\subsection{Fungal Growth Measurement}

The inoculated Petri dishes were observed after 3, 7, 10 and 14 days, and two perpendicular colony diameters were measured; a weekly schedule was applied for longer incubation times (from 14 to 56 days). After 14 days of incubation ( 56 days for $a_{w} \leq 0.90$ ), the plates were sealed in plastic bags and stored at $-20^{\circ} \mathrm{C}$ before mycotoxin analysis.

\subsection{Mycotoxin Analysis}

Ochratoxin A, CPA, PR-toxin, MPA, ROQ-C, PA and CIT were considered as produced by the proper fungi (reported in Table 5); they were measured at the end of the incubation time (14 day old cultures).

\subsubsection{Reagents and Standards}

The chemicals and solvents used for the extraction and clean-up solutions were ACS grade or equivalent (Carlo Erba, Milan, Italy). All the water used was de-ionized and, for HPLC, purified through a Milli-Q treatment system (Millipore, London, UK). For HPLC analysis, methanol and acetonitrile were HPLC grade (Merck, Darmstadt, Germany). Mycotoxin standards were obtained from Sigma-Aldrich (St. Louis, MO, USA) and Biopure (Tulln, Austria). Working standard solutions were prepared by dilution with acetonitrile and kept at $-20^{\circ} \mathrm{C}$.

\subsubsection{Toxin Extraction}

Toxin extraction was performed by putting the fungal colony and agar media in a flask containing $40 \mathrm{~mL}$ of acetonitrile. Then, the mix was vigorously shaken using a rotary-shaking stirrer for $1 \mathrm{~h}$ in order to smash the agar medium into little pieces, filtered (folded filter paper $595 \frac{1}{2}$, Whatman, Sigma-Aldrich, St. Louis, MO, USA) and diluted using the HPLC mobile phase before being analyzed.

\subsubsection{HPLC-MS/MS Analysis}

The mycotoxins (STC, CPA, CIT, ROQ, MPA, OTA, PR toxin, PA), were analyzed using an HPLC-MS/MS system, consisting of a LC 1.4 Surveyor pump, a Quantum Discovery Max triple-quadrupole mass spectrometer (Thermo-Fisher Scientific, San Jose, CA, USA) and a PAL 1.3.1 sampling system (CTC Analitycs AG, Zwingen, Switzerland); the system was controlled by Xcalibur 1.4 software (Thermo-Fisher). The mycotoxins were separated on a Betasil RP-18 column ( $5 \mu \mathrm{m}$ particle size, $150 \times 2.1 \mathrm{~mm}$, Thermo-Fisher); except for PA, a mobile-phase gradient water-acetonitrile (both acidified with $0.2 \%$ formic acid) from $65: 35$ to $25: 75$ in $6 \mathrm{~min}$, then isocratic for $5 \mathrm{~min}$ was used; for PA, the mobile-phase gradient water-acetonitrile (both acidified with $0.2 \%$ formic acid) was from $40: 60$ to 10:90 in $5 \mathrm{~min}$, then isocratic for $3 \mathrm{~min}$. The flow rate was always $0.2 \mathrm{~mL} / \mathrm{min}$ and the injection volume $20 \mu \mathrm{L}$. The ionization was carried out with an ESI interface (Thermo-Fisher) in positive mode as follows: spray capillary voltage $4200 \mathrm{kV}$, sheath and auxiliary gas 35 and $10 \mathrm{psi}$, respectively, temperature of the heated capillary $270{ }^{\circ} \mathrm{C}$. The selected fragment ions and the parent ion [M] ${ }^{+}$were: 310,281 and $253 \mathrm{~m} / z$ for STC ([M] $\left.]^{+} 325 \mathrm{~m} / z\right) ; 196,182$ and $140 \mathrm{~m} / z$ for CPA ([M] $\left.]^{+} 337 \mathrm{~m} / z\right) ; 233,205$ and $191 \mathrm{~m} / z$ 
for CIT ([M] $\left.{ }^{+} 251 \mathrm{~m} / z\right) ; 334,322$ and $193 \mathrm{~m} / z$ for ROQ-C ([M] $\left.{ }^{+} 390 \mathrm{~m} / z\right) ; 303,275$ and $207 \mathrm{~m} / \mathrm{z}$ for MPA ([M] $321 \mathrm{~m} / z) ; 358,341$ and $239 \mathrm{~m} / z$ for OTA ([M] ${ }^{+} 404 \mathrm{~m} / \mathrm{z}$ ); 279, 173, 161 and $145 \mathrm{~m} / \mathrm{z}$ for PR toxin $\left([\mathrm{M}]^{+} 321 \mathrm{~m} / z\right) ; 616,558$ and $332 \mathrm{~m} / z$ for PA ([M] $\left.]^{+} 634\right)$. The collision energy was different for each mycotoxin (ranging from 15 to $33 \mathrm{~V}$ ) and the argon collision pressure was $1.5 \mathrm{mTorr}$. Quantitative determination was performed using LC-Quan 2.0 software (Thermo-Fisher Scientific); LODs were $30 \mu \mathrm{g} / \mathrm{L}$ for MPA, CPA, PR-toxin, PA and STC, $20 \mu \mathrm{g} / \mathrm{L}$ for ROQ-C, $10 \mu \mathrm{g} / \mathrm{L}$ for CIT and OTA.

\subsection{Data Analyses}

Statistical analyses were performed using SPSS v.23 (SPSS Inc., Armonk, NY, USA, 2012). Mycotoxin production data were statistically compared by using a OneWay-ANOVA Test transforming all values by $\mathrm{y}=\ln$ before analysis to homogenize the variance. Tukey test was applied to highlight significant differences between means.

Data on fungal growth, intended as the fungal culture diameter, at different $\mathrm{T}$ or $a_{w}$ regimes, were considered separately for each incubation time. They were standardized (rated on the maximum value observed), to obtain relative growth in a $0-1$ scale, with $0=$ no growth, and $1=$ maximum growth. Relative growth of each fungus, at all incubation times, were jointly analyzed. Thirty six mean values were used for T ( $9 \mathrm{~T}$ regimes and 4 incubation times, mean of 3 replicates) and 20 values for $a_{w}$ ( $5 a_{w}$ regimes and 4 incubation times, mean of 3 replicates). The same approach was applied to obtain relative mycotoxin production. Different nonlinear regression models were fitted to the rate data in order to describe fungal growth and mycotoxin production as function of $\mathrm{T}$ and $a_{w}$; the equation parameters were estimated applying the non-linear regression procedure of the statistical package PASW SPSS statistics v.23 (SPSS Inc., Armonk, NY, USA, 2012) which minimizes the residual sum squares using the Levenberg-Marquardt algorithm. The best model was chosen based on the adjusted $R^{2}$ and on the number of iterations required by the algorithm to converge on parameter estimates, as indicators of goodness of fit.

Minitab 17 (Minitab Inc., State College, PA, USA) was used to develop the surface response contour plots of data, in relation to the combinations $\mathrm{T} \times$ time of incubation and $a_{w} \times$ time of incubation, for each considered fungus. For each combination $\mathrm{T} \times$ time or $a_{w} \times$ time, relative growth, computed as previously described, was used as input for data plotting (relative growth values were transformed from $0-1$ scale to $0-100$ scale to satisfy the type of data input requested by Minitab). Two-dimension surface response contour plots were drawn, with five quoted lines (contour levels): $0 \%, 25 \%, 50 \%, 75 \%$ and $100 \%$ of the relative growth. This kind of data presentation is considered useful when many data are collected in the study and it is not easy to report all data and to compare and comment results.

In order to represent the combined effect of $\mathrm{T}$ and $a_{w}$, the equations developed to describe fungal growth as function of these two variables were combined and the $50 \%$ relative growth values obtained for each fungus were plotted.

Acknowledgments: The present work was supported by the Consorzio per la tutela del Formaggio Grana Padano and the Consorzio del Formaggio Parmigiano Reggiano. Simone Decontardi carried out this work within the PhD School "Agrisystem" of the Università Cattolica del Sacro Cuore (Italy).

Author Contributions: P.B., M.C.L., S.D. and A.P. conceived and designed the experiments; S.D. performed the experiments; M.C.L. and P.B. analyzed the data; T.B. and S.D. contributed reagents/materials/analysis tools; S.D., M.C.L. and P.B. wrote the paper.

Conflicts of Interest: The authors declare no conflict of interest.

\section{References}

1. Banjara, N.; Suhr, M.J.; Hallen-Adams, H.E. Diversity of yeast and mold species from a variety of cheese types. Curr. Microbiol. 2015, 70, 792-800. [CrossRef] [PubMed]

2. Gkatzionis, K.; Yunita, D.; Linforth, R.S.T.; Dickinson, M.; Dodd, C.E.R. Diversity and activities of yeasts from different parts of a Stilton cheese. Int. J. Food Microbiol. 2014, 107, 109-116. [CrossRef] [PubMed] 
3. Cogan, T.M.; Hill, C. Cheese starter cultures. In Cheese: Chemistry, Physics and Microbiology; Fox, P.F., Ed.; Springer: New York, NY, USA, 1993; Volume 1, pp. 193-255.

4. De Santi, M.; Sisti, M.; Barbieri, E.; Piccoli, G.; Brandi, G.; Stocchi, V. A combined morphologic and molecular approach for characterizing fungal microflora from a traditional Italian cheese (Fossa cheese). Int. Dairy J. 2010, 20, 465-471. [CrossRef]

5. Malacarne, M.; Summer, A.; Panari, G.; Pecorari, M. Caratterizzazione chimico-fisica della maturazione del Parmigiano-Reggiano. Sci. Tec. Latt. Casearia 2006, 57, 215-228.

6. Cakmakci, S.; Gundogdu, E.; Hayaloglu, A.A.; Dagdemir, E.; Gurses, M.; Cetin, B.; Tahmas-Kahyaoglu, D. Chemical and microbiological status and volatile profiles of mouldy Civil cheese, a Turkish mould-ripened variety. Int. J. Food Sci. Technol. 2012, 47, 2405-2412. [CrossRef]

7. Milani, E.; Shahidi, F.; Mortazavi, S.A.; Reza Vakili, S.A.; Ghoddusi, H.B. Microbiological, biochemical and rheological changes throughout ripening of kurdish cheese. J. Food Saf. 2014, 34, 168-175.

8. Schiavano, G.F.; Barbieri, E.; Sisti, M.; Gioacchini, A.M.; de Santi, M.; Vallorani, L.; Casadei, L.; Piccoli, G.; Guescini, M.; Stocchi, V.; et al. Characterization of microflora and volatile organic compounds of Fossa (pit) cheese. Ind. Aliment. 2012, 51, 19-32.

9. Gaborit, P.; Menard, A.; Morgan, F. Impact of ripening strains on the typical flavour of goat cheeses. Int. Dairy J. 2001, 11, 315-325.

10. Gripon, J.C. Mould-ripened cheese. In Cheese Chemistry, Physics and Microbiology, Major Cheese Groups; Fox, P.F., Ed.; Elsevier Science Publisher Ltd.: Cambridge, UK, 1993; Volume 2.

11. Panelli, S.; Buffoni, J.S.; Bonacina, C.; Feligini, M. Identification of moulds from the Taleggio cheese environment by the use of DNA barcodes. Food Control 2012, 28, 385-391. [CrossRef]

12. Battilani, P.; Pietri, A.; Giorni, P.; Formenti, S.; Bertuzzi, T.; Toscani, T.; Virgili, R.; Kozakiewicz, Z. Penicillium population in dry-cured ham manufacturing plants. J. Food Prot. 2007, 70, 975-980. [CrossRef] [PubMed]

13. Comi, G.; Chiesa, L.; Panseri, S.; Orlic, S.; Iacumin, L. Evaluation of different methods to prevent Penicillium nordicum growth on and ochratoxin A production in country-style sausages. World Mycotoxin J. 2013, 6, 411-418. [CrossRef]

14. Rodríguez, A.; Rodríguez, M.; Martín, A.; Núñez, F.; Córdoba, J.J. Evaluation of hazard of aflatoxin $B_{1}$, ochratoxin A and patulin production in dry-cured ham and early detection of producing moulds by qPCR. Food Control 2012, 27, 118-126. [CrossRef]

15. Filtenborg, O.; Frisvad, J.C.; Thrane, U. Moulds in food spoilage. Int. J. Food Microbiol. 1996, 33, 85-102. [CrossRef]

16. Hymery, N.; Vasseur, V.; Coton, M.; Mounier, J.; Jany, J.L.; Barbier, G.; Coton, E. Filamentous fungi and mycotoxins in cheese: A review. Compr. Rev. Food Sci. Food Saf. 2014, 13, 437-456. [CrossRef]

17. Chang, S.C.; Wei, Y.H.; Wei, D.L.; Chen, Y.Y.; Jong, S.C. Factors affecting the production of eremofortin C and PR toxin in Penicillium roqueforti. Appl. Environ. Microbiol. 1991, 57, 2581-2585. [PubMed]

18. Bailly, J.D.; Querin, A.; Le Bars-Bailly, S.; Benard, G.; Guerre, P. Citrinin production and stability in cheese. J. Food Prot. 2002, 65, 1317-1321. [CrossRef] [PubMed]

19. Le Bars, J. Cyclopiazonic acid production by Penicillium camemberti thom and natural cccurrence of this mycotoxin in cheese. Appl. Environ. Microbiol. 1979, 6, 1052-1055.

20. Taniwaki, M.H.; Hocking, A.D.; Pitt, J.I.; Fleet, G.H. Growth and mycotoxin production by fungi in atmospheres containing 80\% carbon dioxide and 20\% oxygen. Int. J. Food Microbiol. 2010, 143, 218-225. [CrossRef] [PubMed]

21. Lund, F.; Filtenborg, O.; Frisvad, J.C. Associated mycoflora of cheese. Food Microbiol. 1995, 12, $173-180$. [CrossRef]

22. Wagener, R.E.; Davis, N.D.; Diener, U.L. Penitrem A and roquefortine production by Penicillium commune. Appl. Environ. Microbiol. 1980, 39, 882-887. [PubMed]

23. Erdogan, A.; Sert, S. Mycotoxin-forming ability of two Penicillium roqueforti strains in blue moldy tulum cheese ripened at various temperatures. J. Food Prot. 2004, 67, 533-535. [CrossRef] [PubMed]

24. Finoli, C.; Vecchio, A.; Galli, A.; Dragoni, I. Roquefortine C occurrence in blue cheese. J. Food Prot. 2001, 64, 246-251. [CrossRef] [PubMed]

25. Taniwaki, M.H.; van Dender, A.G.F. Growth of fungi and mycotoxin production on cheese under modified atmospheres. Int. J. Food Microbiol. 2001, 68, 125-133. [CrossRef] 
26. Schmidt-Heydt, M.; Graf, E.; Stoll, D.; Rolf, G. The biosynthesis of ochratoxin A by Penicillium as one mechanism of adaptation to $\mathrm{NaCl}$ rich foods. Food Microbiol. 2012, 29, 233-241. [CrossRef] [PubMed]

27. Samson, R.A.; Frisvad, J.C. Penicillium subgenus Penicillium: New taxonomy schemes and mycotoxins and other extrolites. Stud. Mycol. 2004, 49, 1-266.

28. Altug, T. Introduction to Toxicology and Food; CRC Press: Boca Raton, FL, USA, 2003; pp. 1-168.

29. Abd Alla, E.A.; Metwally, M.M.; Mehriz, A.M.; Abu Sree, Y.H. Sterigmatocystin-incidence, fate and production by A. versicolor in Ras cheese. Mycotoxin Res. 1997, 13, 61-66. [CrossRef]

30. Metwally, M.; El-Sayed, A.A.; Mehriz, A.; Abu, S.Y. Toxigenic fungi isolated from Roquefort cheese. Mycopathologia 1979, 66, 187-190.

31. Northolt, M.D.; Egmond, H.P.V.; Soentoro, P.; Deijll, E. Fungal growth and the presence of sterigmatocystin in hard cheese. J. Assoc. Off. Anal. Chem. 1980, 63, 115-119. [PubMed]

32. Rank, C.; Nielsen, K.F.; Larsen, T.O.; Varga, J.; Samson, R.A.; Frisvad, J.C. Distribution of sterigmatocystin in filamentous fungi. Fungal Biol. 2011, 115, 406-420. [CrossRef] [PubMed]

33. Engel, G.; von Milczewski, K.E.; Prokopek, D.; Teuber, M. Strain-specific synthesis of Mycophenolic acid by Penicillium roqueforti in blue-veined cheese. Appl. Environ. Microbiol. 1982, 43, 1034-1040. [PubMed]

34. Lafont, P.; Siriwardana, M.G.; Lafont, J. Contamination of cheeses by mycotoxins. Med. Nutr. 1979, 15, $257-262$.

35. Zambonin, C.G.; Monaci, L.; Aresta, A. Determination of cyclopiazonic acid in cheese samples using solid-phase microextraction and high performance liquid chromatography. Food Chem. 2011, 75, $249-254$. [CrossRef]

36. Ammar, H.; Michailis, G.; Lisovsky, T. A screen of yeast respiratory mutants for sensitivity against the mycotoxin citrinin identifies the vascular ATPase as an essential factor for the toxicity mechanism. Curr. Genet. 2000, 37, 277-284. [CrossRef] [PubMed]

37. Singh, N.D.; Sharma, A.K.; Dwivedi, P.; Patil, R.D.; Kumar, M. Citrinin and endosulfan induced maternal toxicity in pregnant wistar rats: Pathomorphological study. J. Appl. Toxicol. 2007, 27, 589-601. [CrossRef] [PubMed]

38. Ostry, V.; Malir, F.; Ruprich, J. Producers and important dietary sources of ochratoxin A and citrinin. Toxins 2013, 5, 1574-1586. [CrossRef] [PubMed]

39. Erdogan, A.; Gurses, M.; Sert, S. Isolation of moulds capable of producing mycotoxins from blue mouldy Tulum cheeses produced in Turkey. Int. J. Food Microbiol. 2003, 85, 83-85. [CrossRef]

40. Fernandez-Bodega, M.A.; Mauriz, E.; Gomez, A.; Martin, J.F. Proteolytic activity, mycotoxins and andrastin A in Penicillium roqueforti strains isolated from Cabrales, Valdeon and Bejes-Tresviso local varieties of blue-veined cheeses. Int. J. Food Microbiol. 2009, 136, 18-25. [CrossRef] [PubMed]

41. Cakmakci, S.; Gurses, M.; Hayaloglu, A.A.; Cetin, B.; Sekerci, P.; Dagdemir, E. Mycotoxin production capability of Penicillium roqueforti in strains isolated from mould-ripened traditional Turkish civil cheese. Food Addit. Contam. Part A 2015, 32, 245-249. [CrossRef] [PubMed]

42. Siemens, K.; Zawistowski, J. Occurrence of PR imine, a metabolite of Penicillium roqueforti, in Blue cheese. J. Food Prot. 1993, 56, 317-319. [CrossRef]

43. Minervini, F.; Monaci, L.; Montagna, M.T.; Dragoni, I. Assessment of mycotoxin production by Aspergillus and Penicillium fungi isolated from dairy products. Ind. Aliment. 2002, 41, 1336-1340.

44. Dall'Asta, C.; De Dea Lindner, J.; Galaverna, G.; Dossena, A.; Neviani, E.; Marchelli, R. The occurrence of ochratoxin A in blue cheese. Food Chem. 2008, 106, 729-734. [CrossRef]

45. Analytis, S. Über die relation zwischen biologischer entwicklung und temperatur bei phytopathogenen pilzen. J. Phytopathol. 1977, 90, 64-76. [CrossRef]

46. Grimm, K.; Ram, N. Nonlinear growth curves in developmental research. Child Dev. 2011, 82, $1357-1371$. [CrossRef] [PubMed]

47. Marin, P.; Palmero, D.; Jurado, M. Effect of solute and matric potential on growth rate of fungal species isolated from cheese. Int. Dairy J. 2014, 36, 89-94. [CrossRef]

48. Fontaine, K.; Hymery, N.; Lacroix, M.Z.; Puel, S.; Puel, O.; Rigalma, K.; Gaydou, V.; Coton, E.; Mounier, J. Influence of intraspecific variability and abiotic factors on mycotoxin production in Penicillium roqueforti. Int. J. Food Microbiol. 2015, 215, 187-193. [CrossRef] [PubMed]

49. Giorni, P.; Magan, N.; Pietri, A.; Battilani, P. Growth and aflatoxin production of an Italian strain of Aspergillus flavus: Influence of ecological factors and nutritional substrates. World Mycotoxin J. 2011, 4, 425-432. [CrossRef] 
50. Manabe, M. Fermented foods and mycotoxins. Mycotoxins 2001, 51, 25-28. [CrossRef]

51. Samson, R.A.; Houbraken, J.; Thrane, U.; Frisvad, J.C.; Andersen, B. Food and Indoor Fungi; CBS KNAW Biodiversity Center: Utrecht, The Netherlands, 2010; p. 390.

52. Larsen, T.O.; Gareis, M.; Frisvad, J.C. Cell cytotoxicity and mycotoxin and secondary metabolite production by common penicillia on cheese agar. J. Agric. Food Chem. 2002, 50, 6148-6152. [CrossRef] [PubMed]

53. Kokkonen, M.; Jestoi, M.; Rizzo, A. The effect of substrate on mycotoxin production of selected Penicillium strains. Int. J. Food Microbiol. 2005, 99, 207-214. [CrossRef] [PubMed]

54. Eriksen, G.S.; Moldes-Anaya, A.; Faeste, C.K. Penitrem A and analogues: Toxicokinetics, toxicodynamics including mechanism of action and clinical significance. World Mycotoxin J. 2013, 6, 263-272. [CrossRef]

55. Tancinova, D.; Mokry, M.; Barborakova, Z.; Maskova, Z. Mycobiota of spices and aromatic herbs. Potravin. Sci. J. Food Ind. 2014, 8, 172-177.

56. Kokkonen, M.; Jestoi, M.; Rizzo, A. Determination of selected mycotoxins in mould cheeses with liquid chromatography coupled to tandem with mass spectrometry. Food Addit.Contam. 2005, 22, 449-456. [CrossRef] [PubMed]

57. Polonsky, J.; Merrien, M.A.; Scott, P.M. Roquefortine and isofumigaclavine A, alkaloids from Penicillium roqueforti. Ann. Nutr. Aliment. 1977, 31, 963-968. [PubMed]

58. Cheeseman, K.; Ropars, J.; Renault, P.; Dupont, J.; Gouzy, J.; Branca, A.; Abraham, A.L.; Ceppi, M.; Conseiller, E.; Debuchy, R.; et al. Multiple recent horizontal transfers of a large genomic region in cheese making fungi. Nat. Commun. 2014, 5, 2876. [CrossRef] [PubMed]

59. Van Egmond, H.P. Mycotoxins in dairy products. Food Chem. 1983, 11, 289-307. [CrossRef]

60. Schmidt-Heydt, M.; Magan, N.; Geisen, R. Stress induction of mycotoxin biosynthesis genes by abiotic factors. FEMS Microbiol. Lett. 2008, 284, 142-149. [CrossRef] [PubMed]

61. Rossi, V.; Pattori, E.; Ravanetti, A.; Giosuè, S. Effect of constant and fluctuating temperature regimes on sporulation of four fungi causing head blight of wheat. J. Plant Pathol. 2002, 84, 95-105.

62. Nazari, L.; Manstretta, V.; Rossi, V. A non-linear model for temperature-dependent sporulation and T-2 and HT-2 production of Fusarium langsethiae and Fusarium sporotrichioides. Fungal Biol. 2016, 120, 562-571. [CrossRef] [PubMed]

63. Battilani, P.; Camardo Leggieri, M.; Rossi, V.; Giorni, P. AFLA-maize, a mechanistic model for Aspergillus flavus infection and aflatoxin $\mathrm{B}_{1}$ contamination in maize. Comput. Electron. Agric. 2013, 94, 38-46. [CrossRef]

64. Battilani, P.; Camardo Leggieri, M. OTA-grapes, a mechanistic model to predict ochratoxin A risk in grapes, a step beyond the systems approach. Toxins 2015, 7, 3012-3029.

65. Dantigny, P.; Guilmart, A.; Bensoussan, M. Basis of predictive mycology. Int. J. Food Microbiol. 2005, 100, 187-196. [CrossRef] [PubMed]

66. Garcia, D.; Ramos, A.J.; Sanchis, V.; Marín, S. Modelling mould growth under suboptimal environmental conditions and inoculum size. Food Microbiol. 2010, 27, 909-917. [CrossRef] [PubMed]

67. Rossi, V.; Giosuè, S.; Caffi, T. Modelling plant diseases for decision making in crop protection. In Precision Crop Protection-The Challenge and Use of Heterogeneity; Oerke, E.C., Gerhards, R., Menz, G., Sikora, R.A., Eds.; Springer: Dordrecht, The Netherlands, 2010; pp. 241-258.

68. Giorni, P.; Camardo Leggieri, M.; Magan, N.; Battilani, P. Comparison of ecological needs for sporulation of Aspergillus flavus sclerotia on natural and artificial substrates. Fungal Biol. 2012, 116, 637-742. [CrossRef] [PubMed]

69. Frisvad, J.C.; Smedsgaard, J.; Larsen, T.O.; Samson, R.A. Mycotoxins, drugs and other extrolites produced by species in Penicillium subgenus Penicillium. Stud. Mycol. 2004, 49, 201-241.

70. Dallyn, H.; Fox, A. Spoilage of material of reduced water activity by xerophilic fungi. In Microbial Growth and Survival in Extremes of Environment; Gould, G.H., Corry, J.E.L., Eds.; Academic Press: London, UK, 1980; Volume 15, pp. 129-139.

71. Pitt, J.I. The Genus Penicillium and Its Teleomorphic States Eupenicillium and Talaromyces; Academic Press Inc.: London, UK, 1979.

(C) 2016 by the authors; licensee MDPI, Basel, Switzerland. This article is an open access article distributed under the terms and conditions of the Creative Commons Attribution (CC-BY) license (http://creativecommons.org/licenses/by/4.0/). 